https://journal-computing.org/index.php/journal-cisa/index

\title{
Analisis Perubahan Vegetasi Di Kecamatan Tingkir Kota Salatiga Menggunakan Metode NDVI
}

\section{Oktovio Metusael Kenspasio Kapoh1, Frederik Samuel Papilaya²}

\author{
1,2Fakultas Teknologi Informasi, Universitas Kristen Satya Wacana \\ Email: 1682017047@student.uksw.edu, 2samuel.papilaya@uksw.edu
}

\begin{abstract}
Abstrak
Analisis vegetasi adalah metode yang dilakukan untuk mengetahui seberapa besar sebaran berbagai macam spesies yang ada dalam suatu area. Kegiatan ini umumnya dilakukan melalui pengamatan langsung dan dilakukan pula dengan membuat plot, serta mengamati morfologi dan identifikasi vegetasi yang ada. Bentuk atau struktur vegetasi yang dimaksud ialah bentuk pertumbuhan, stratifikasi dan tutupan tajuk. Sistem Informasi Geografis sangat diperlukan untuk melihat jenis vegetasi yang berada pada wilayah penelitian yang di lakukan, indeks vegetasi yang diperlukan diantaranya indeks NDVI (Normalized Difference Vegetation Index). Dengan metode inilah langkah langkah dalam melakukan Analisis Perubahan dapat diketahui sebelumnya sehingga dapat membantu Analisis Perubahan Tingkat Kerapatan Vegetasi Menggunakan Landsat 8 Oli Di Kecamatan Tingkir Kota Salatiga.
\end{abstract}

Kata Kunci: NDVI, Vegetasi

\section{PENDAHULUAN}

Kecamatan Tingkir berada di bagian selatan kota Salatiga. Luas dari pada kecamatan tingkir adalah 1.054,852 Ha dan Persentase 18,58\%. Ada 2 bagian luas yang terbagi di Kecamatan Tingkir Kota Salatiga ini yaitu lahan sawah dan lahan bukan sawah. Lahan sawah sebesar 311,94, lahan bukan sawah sebesar 742,91, jumlah dari lahan sawah dan lahan bukan sawah yaitu sebesar 1.054,85. Jumlah penduduk di Kecamatan Tingkir Kota Salatiga 40.398 jiwa, dengan kepadatan penduduk yang terpadat di Kota Salatiga sendiri adalah Kecamatan Tingkir Kota Salatiga dengan kepadatan 38 jiwa/ha, yang paling rendah kepadatan di Kota Salatiga yaitu Kecamatan Argomulyo dengan kepadatan 22 jiwa/ha, dan luas wilayah di 
https://journal-computing.org/index.php/journal-cisa/index

Kecamatan Tingkir Kota Salatiga yaitu 1.054,85 Ha. Banyaknya rumah tangga dan rata-rata anggota rumah tangga di Kecamatan Tingkir Kota Salatiga yaitu 40.398 penduduk, 10.372 rumah tangga dan rata rata anggota rumah tangga 4 . Kehadiran vegetasi pada suatu landsat akan memberikan dampak positif bagi keseimbangan ekosistem dalam skala yang lebih luas. Secara umum peranan vegetasi dalam suatu ekosistem terkait dengan pengaturan keseimbangan karbon dioksida dan oksigen dalam udara, perbaikan sifat fisik, kimia dan biologis tanah, pengaturan tata air tanah dan lain-lain [1].

Laju perubahan penggunaan tanah di Kecamatan Tingkir Kota Salatiga dari daerah pertanian ke permukiman dan kawasan industri dari tahun ke tahun terus mengalami perubahan. Berdasarkan masalah yang terjadi perlu dilakukan analisis untuk mengetahui daerah mana saja yang mengalami perubahan lahan atau konversi lahan, daerah mana yang mengalami perubahan paling signifikan. Pada penelitian ini juga menggunakan LANDSAT 8 OLI untuk melihat perubahan yang terjadi dari tahun ke tahun dan menggunakan metode Normalized Difference Vegetation Index (NDVI) untuk melihat jenis vegetasinya yang berada pada wilayah penelitian yang dilakukan [2]. Analisis ini dapat digunakan menjadi bahan pertimbangan bagi Dinas Tata Ruang dan Permukiman dalam melakukan penyusunan dan pengendalian tata ruang serta pelaksanaan perizinan banggunan untuk tahun atau periode yang akan datang, supaya dalam perencanaan atau permintaan ijin tidak menimbulkan masalah, baik bagi penduduk maupun lingkungan.

Metode deskriptif dengan analisis NDVI (Normalized Difference Vegetation Index) untuk memperoleh data langsung di komputer menggunakan citra Landsat 8 dan software ArcGis 10.4, serta survei lapangan ke uji akurasi dengan metode pengambilan titik koordinat [3]. Mengetahui struktur dan komposisi vegetasi baik pohon maupun vegetasi penutup lantai (lower crop community-LCC) di lokasi kajian AMDAL kecamatan Ampel Kabupaten Boyolali; serta mengetahui pengaruh indeks nilai penting dan indeks diversitas 


\section{Journal of Computer and Information Systems Ampera}

Vol. 2, No. 3, September 2021 e-ISSN: 2775-2496

https://journal-computing.org/index.php/journal-cisa/index

vegetasi terhadap kondisi lingkungan di sekitar lokasi kajian AMDAL kecamatan Ampel kabupaten Boyolali [4].

\section{METODE PENELITIAN}

Kegiatan penelitian ini dilaksanakan di Kecamatan Tingkir Kota Salatiga Provinsi Jawa Tengah, Indonesia. Metode analisis yang digunakan dalam penelitian ini yaitu dengan menggunakan metode overlay. Overlay dilakukan pada citra Landsat 8 yang telah diklasifikasikan NDVI (Normalized Difference Vegetation Index) dilakukan menggunakan software qgis 2.18.25, dan menghitung persentase dari setiap klasifikasi warna untuk mengetahui Perubahan Tingkat Kerapatan Vegetasi Penelitian ini menggunakan metode analisis overlay. Overlay dilakukan pada citra Landsat 8 yang telah diklasifikasikan NDVI pada setiap tahun (2016 - 2020) di Kota Salatiga, dilanjutkan dengan melakukan overlay pada Setiap Kecamatan di Salatiga untuk mengetahui wilayah mana yang mengalami perubahan tingkat kerapatan vegetasi terbesar. Satelit dan Peta Lokasi Kecamatan Tingkir Kota Salatiga dapat dilihat pada Gambar 1.
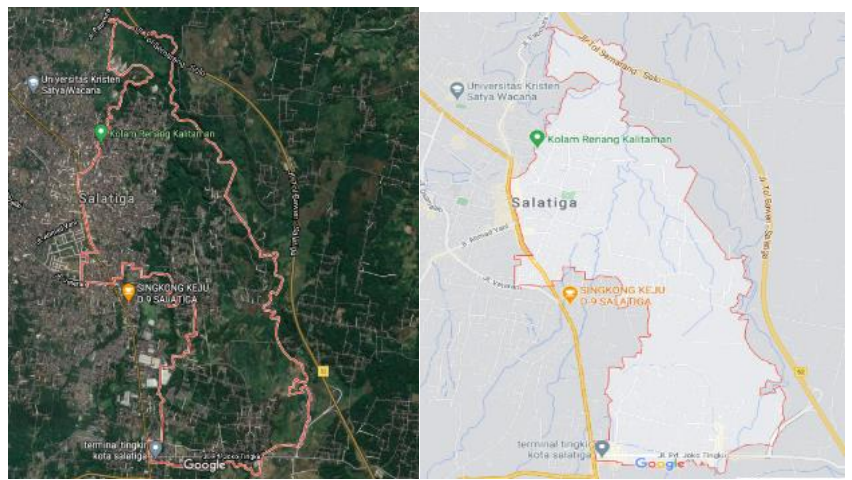

Gambar 1. Wilayah Penelitian Kecamatan Tingkir Kota Salatiga

\section{1) Koreksi Citra}

Pada penelitian ini dilakukan koreksi radiometrik yang digunakan untuk memperbaiki nilai individu-individu piksel pada citra agar 


\section{Journal of Computer and Information Systems Ampera}

Vol. 2, No. 3, September 2021 e-ISSN: 2775-2496

https://journal-computing.org/index.php/journal-cisa/index

sesuai, karena mempertimbangkan faktor atmosfer sebagai sumber kesalahan utama. Koreksi dilakukan dengan plugin semi-automatic classification.

\section{2) Analisis NDVI}

Selanjutnya dilakukan analisis NDVI, dengan memanfaatkan band4 dan band5 dari citra Landsat 8. Analisis ini menggunakan transfomrasi NDVI dengan hasil indeks yang didapatkan berkisar -1 sampai 1.

Nilai NDVI dilihat dengan menggunakan rumus :

Keterangan :

$$
N D V I=\frac{\text { Band NIR }- \text { Band } R}{\text { Band NIR }+ \text { Band } R}
$$

NIR : Infra - merah dekat

R : Merah

NDVI Berkisar dari -1 sampai 1

NDVI : -1 berarti air

NDVI : 0 berarti tanah gundul

NDVI : 1 berarti hijau (lebat)

\section{3) Overlay}

Setelah itu dilakukan pemotongan citra, untuk membatasi area yang diteliti. Pemotongan dilakukan setelah citra tersebut dikoreksi dan dianalisa menggunakan NDVI, pemotongan citra dilakukan sesuai peta administrasi Tingkir, hasil pemotongan citra tersebut akan digunakan dalam proses klasifikasi.

\section{4) Klasifikasi}

Dari hasil survei yang dilakukan dengan membandingkan titik koordinat random hasil overlay dengan Google Earth, berikut ini merupakan tabel klasifikasi dari NDVI. 


\section{Journal of Computer and Information Systems Ampera}

Vol. 2, No. 3, September 2021 e-ISSN: 2775-2496

https://journal-computing.org/index.php/journal-cisa/index

Tabel 1. Nilai NDVI Berdasarkan Kerapatan

\begin{tabular}{|l|l|l|l|}
\hline No & \multicolumn{1}{|c|}{$\begin{array}{c}\text { Kelas } \\
\text { Vegetasi }\end{array}$} & $\begin{array}{c}\text { Nilai } \\
\text { NDVI }\end{array}$ & Keterangan \\
\hline 1 & Non Vegetasi & $<0.1652$ & $\begin{array}{l}\text { Rumah, } \\
\text { Rumput, } \\
\text { Sawah }\end{array}$ \\
\hline 2 & Jarang & $\begin{array}{l}0.1652- \\
0.2814\end{array}$ & $\begin{array}{l}\text { Dominasi } \\
\text { Semak }\end{array}$ \\
\hline 3 & Cukup Lebat & $\begin{array}{l}0.2814- \\
0.319\end{array}$ & Pepohonan \\
\hline 4 & Lebat & $>0.319$ & Hutan \\
\hline
\end{tabular}

Tabel 1 menunjukkan kelas Non Vegetasi menunjukkan rumah, rumput dan sawah, pada kelas Vegetasi Jarang menunjukan perdu dan semak belukar, pada kelas vegetasi cukup lebat di dominasi oleh pepohonan, dan pada kelas vegetasi lebat menunjukan Hutan Kota.

\section{HASIL DAN PEMBAHASAN}

Berdasarkan hasil analisis NDVI diperoleh sebaran nilai kerapatan vegetasi di Kecamatan Tingkir pada tahun 2016 (Gambar 1) yaitu berada pada rentang -0.416883 hingga 0.416883 . Tingkat kerapatan vegetasi berdasarkan nilai NDVI dapat dijadikan sebagai dasar pengkelasan sesuai dengan dominasi tumbuhan (seperti pada Tabel 1).

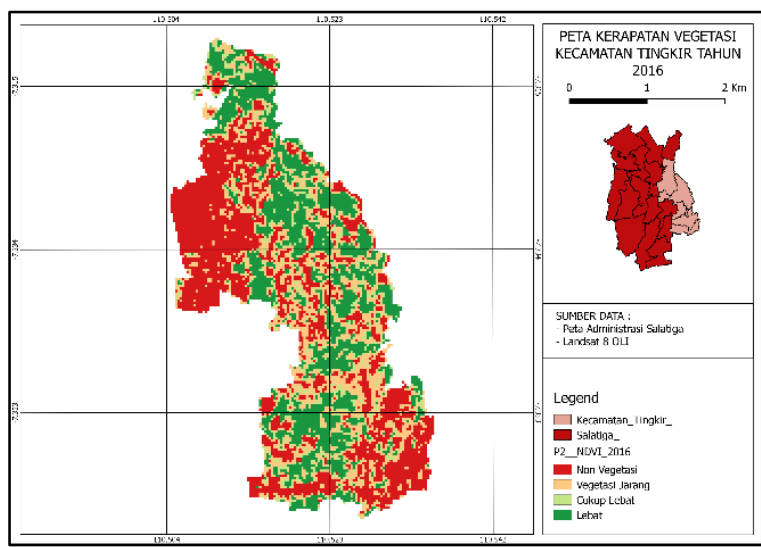

Gambar 2. Peta Kerapatan Vegetasi Tingkir 2016 


\section{Journal of Computer and Information Systems Ampera}

Vol. 2, No. 3, September 2021 e-ISSN: 2775-2496

https://journal-computing.org/index.php/journal-cisa/index

Berdasarkan Gambar 2 nilai NDVI di klasifikasikan berdasarkan kerapatan dan dihitung persentasenya, diikuti dengan tahun tahun lainnya. Berikut ini merupakan Tabel dari NDVI pada Tingkir tahun $2016-2020$.

Tabel 2. Persentase Klasifikasi NDVI Tingkir dari Tahun ke Tahun

\begin{tabular}{|l|l|l|l|l|l|}
\hline Tingkir & 2016 & 2017 & 2018 & 2019 & 2020 \\
\hline $\begin{array}{l}\text { Non } \\
\text { Vegetasi }\end{array}$ & 37,69 & 35,02 & 44,28 & 38,96 & 43,04 \\
\hline $\begin{array}{l}\text { Vegetasi } \\
\text { Jarang }\end{array}$ & 24,90 & 30,19 & 26,93 & 29,77 & 24,75 \\
\hline $\begin{array}{l}\text { Cukup } \\
\text { Lebat }\end{array}$ & 8,66 & 10,26 & 8,63 & 8,98 & 7,58 \\
\hline Lebat & 28,75 & 24,52 & 20,16 & 22,29 & 24,62 \\
\hline
\end{tabular}

Berdasarkan tabel 2 dapat dilihat perubahan vegetasi dari kota salatiga terutama pada tahun 2018, kemudian diikuti perhitungan NDVI pada tiap kelurahan di kecamatan tingkir untuk mengetahui kelurahan mana yang mengalami perubahan Terbesar.

Setelah pembuatan tabel 2 dapat dibuat grafik untuk mengetahui dengan lebih jelas kelurahan dengan perubahan vegetasi terbesar, dari hasil chart dapat dilihat untuk wilayah dengan persentase vegetasi tertinggi terdapat pada Kelurahan Sidorejo Kidul dan sebaliknya wilayah dengan persentase vegetasi terrendah terdapat pada Kelurahan Gendongan, untuk wilayah dengan perubahan persentase non vegetasi tertinggi yaitu Kelurahan Kutowinangun dan sebaliknya perubahan persentase vegetasi tertinggi dimiliki oleh Kelurahan Tingkir Tengah, untuk Perubahan Vegetasi Tertinggi dapat dilihat dari trendline yaitu Kelurahan Kutowinangun.[5] Data yang diperlukan adalah citra digital Landsat-7, citra digital TerraSAR-X, peta Rupa Bumi Indonesia (RBI) skala 1:25.000,[7] 


\section{Journal of Computer and Information Systems Ampera}

Vol. 2, No. 3, September 2021 e-ISSN: 2775-2496

https://journal-computing.org/index.php/journal-cisa/index

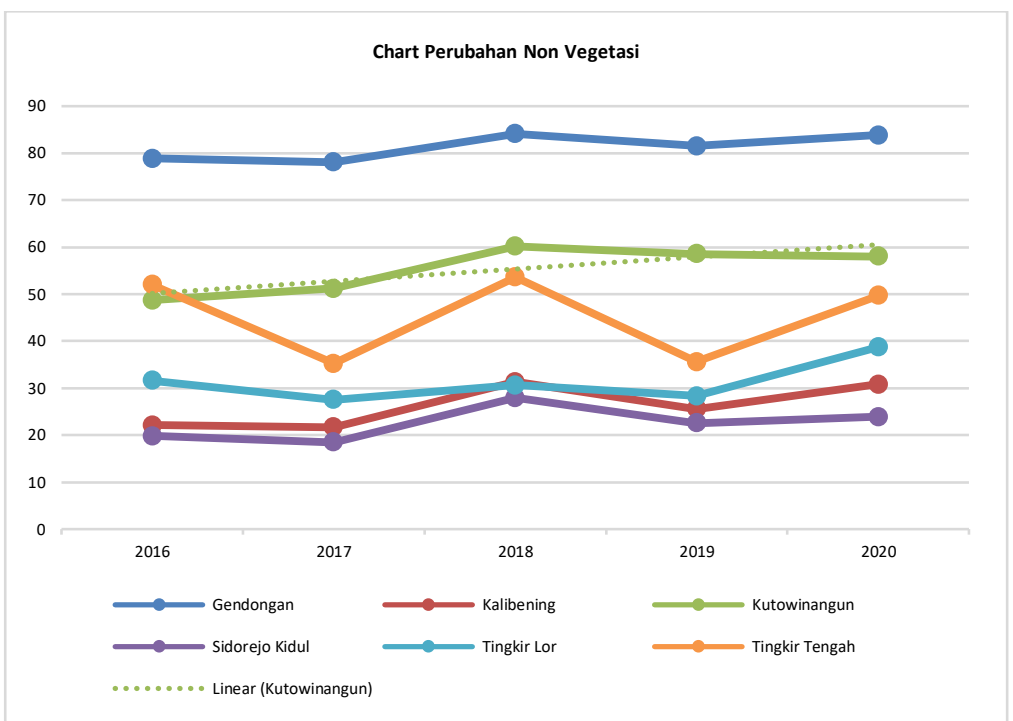

Gambar 3. Grafik Perubahan Persentase Non Vegetasi

\section{KESIMPULAN}

Berdasarkan hasil pembahasan dalam penelitian yang telah dilakukan dapat ditarik kesimpulan yaitu metode NDVI yang diterapkan pada citra Landsat 8 dapat digunakan untuk memperoleh informasi mengenai tutupan vegetasi dan persentase tutupan vegetasi di wilayah penelitian. Hasil penerapan NDVI adalah diketahuinya vegetasi tertinggi terdapat pada Kelurahan Sidorejo Kidul dan sebaliknya wilayah dengan persentase vegetasi terendah terdapat pada Kelurahan Gendongan, untuk wilayah dengan perubahan persentase non vegetasi tertinggi yaitu Kelurahan Kutowinangun dan sebaliknya perubahan persentase vegetasi tertinggi dimiliki oleh Kelurahan Tingkir Tengah, sedangkan untuk perubahan vegetasi tertinggi yaitu Kelurahan Kutowinangun.

\section{DAFTAR PUSTAKA}

[1] D. Toradmalle, J. Muthukuru, and B. Sathyanarayana, "Certificateless and provably-secure digital signature scheme based on elliptic curve," Int. J. Electr. Comput. Eng., vol. 9, no. 4, 
Journal of Computer and Information Systems Ampera

Vol. 2, No. 3, September 2021 e-ISSN: 2775-2496

https://journal-computing.org/index.php/journal-cisa/index

pp. 3228-3231, 2019, doi: 10.11591/ijece.v9i4.ppxx-xx.

[2] badan pusat statistik kota Salatiga, "kecamatan salatiga," Banyaknya Perusahaan Industri Kecil Menengah, Tenaga Kerja, dan Investasi per Kecamatan di Kota Salatiga, 2019, 2019.

https://salatigakota.bps.go.id/statictable/2020/06/30/518/ banyaknya-perusahaan-industri-kecil-menengah-tenagakerja-dan-investasi-per-kecamatan-di-kota-salatiga2019.html (accessed Jan. 12, 2021).

[3] Dwi Yanti et al., "Analisis Kerapatan Vegetasi di Kecamatan Pangandaran melalui Citra Landsat 8," J. Geogr. Edukasi dan Lingkung., vol. 4, no. 1, pp. 32-38, 2020, doi: 10.29405/jgel.v4i1.4229.

[4] D. P. Prabowo, S. Bachri, and B. S. Wiwoho, "Prediksi Perubahan Penggunaan Lahan Dan Pola Berdasarkan Citra Landsat Multiwaktu Dengan Land Change Modeler (Lcm) Idrisi Selva 17: Studi Kasus Sub-Das Brantas Hulu," J. Pendidik. Geogr., vol. 22, no. 1, pp. 32-48, 2017, doi: 10.17977/um017v22i12017p032.

[5] C. R. Case, F. Agustin, and Y. Arifianti, "Ekstraksi Aspek Geomorfologi ( Scarps ) Pada Citra Fusi Landsat 7 dan Terrasar-X untuk Meningkatkan Tingkat Kedetailan Zonasi Kerentanan Gerakan Tanah ( Kasus Kabupaten Cianjur ) The Extraction of Geomorphology Aspects ( Scarps ) on Landsat 7 and Terrasar," vol. 6, no. 1, pp. 9-15, 2015., pp. 413-414.

[6] D. P. Prabowo, S. Bachri, and B. S. Wiwoho, "Prediksi Perubahan Penggunaan Lahan Dan Pola Berdasarkan Citra Landsat Multiwaktu Dengan Land Change Modeler (Lcm) Idrisi Selva 17: Studi Kasus Sub-Das Brantas Hulu," J. Pendidik. Geogr., vol. 22, no. 1, pp. 32-48, 2017, doi: 10.17977/um017v22i12017p032.

[7] C. R. Case, F. Agustin, and Y. Arifianti, "Ekstraksi Aspek Geomorfologi ( Scarps ) Pada Citra Fusi Landsat 7 dan Terrasar$\mathrm{X}$ untuk Meningkatkan Tingkat Kedetailan Zonasi Kerentanan Gerakan Tanah ( Kasus Kabupaten Cianjur ) The Extraction of Geomorphology Aspects ( Scarps ) on Landsat 7 and Terrasar," vol. 6, no. 1, pp. 9-15, 2015., pp. 413-414. 